\title{
Chronic Bacterial Prostatitis
}

National Cancer Institute

\section{Source}

National Cancer Institute. Chronic Bacterial Prostatitis. NCI Thesaurus. Code C92956.

A chronic infection of the prostate gland caused by bacteria. It is manifested with recurring urinary tract infections. The culture of the prostatic fluid, semen, or postmassage urine specimen reveals the presence of bacteria. 